\title{
Integrating Process and Ontology for Supply Chain Modelling
}

\author{
Tonci Grubic, Ip-Shing Fan \\ Manufacturing Department, School of Applied Sciences, Cranfield University \\ t.grubic@cranfield.ac.uk, i.s.fan@cranfield.ac.uk
}

\begin{abstract}
This paper introduces an ontology model developed to support supply chain process modelling. Supply chain provides the business context for achieving interoperability of enterprise systems. It is observed that the emphasis on ontology development for enterprise interoperability could result in information models that are not relevant to real business needs. This work explicitly defines the generic business processes relevant to supply chain operations and develops the ontology that was tested in the creation of the information model to support the information exchange needs three industry case studies. It demonstrated that prior identification of processes the ontology is supposed to support facilitates its development and also its subsequent validation. This paper introduces the overall ontology development approach together with some of the findings that summarise our experiences in developing the ontology model to support supply chain process modelling.
\end{abstract}

\section{Introduction}

The interest in supply chain modelling has been steadily increasing ever since the topic of supply chain management has started to evolve some 25 years ago. During this time many supply chain modelling approaches were proposed. Based on the inputs and objectives of a supply chain study, [1] divides supply chain modelling approaches into four categories: (1) deterministic analytical models, (2) stochastic analytical models, (3) economic models, and (4) simulation models. The evolution of supply chain models, in the light of information technology advances, is found in [2]. Besides the first three categories mentioned by [1], [2] also acknowledge the presence of so called IT-driven models. These models aim to integrate and coordinate various phases of supply chain planning by employing recently developed application software such as ERP or Warehouse Management Systems.

Furthermore, [3] classify supply chain models into three categories: (1) optimization models, (2) analytical performance models, and (3) simulation models. The major foci of optimisation models are to find the location of different facilities (production, distribution, warehousing) or paths through which different material goods will flow. These models correspond with the first category of approaches proposed by [1]. The second category of approaches aims to address the stochastic and dynamic nature of supply chains by employing the methods which enable modelling and representation of such systems. Hence, this category includes approaches such as Markov chains or Petri nets. According to [3], due to their intrinsic characteristics, the first two categories do not enable accurate and detailed representation of supply chains in a manner as simulation approaches do.

Thus, [4] classify supply chain simulation models into three groups: (1) discrete-event simulation, (2) system dynamics, and (3) agent-based modelling and simulation. Further, [5] claims that the choice of supply chain simulation approach depends on the problem aimed to be solved. However, according to [6] what is missing in all supply chain modelling approaches is the lack of common supply chain modelling framework. Others, e.g. [3, 7-11], have also recognized the lack of common supply chain modelling framework and proposed solutions accordingly. Although these approaches attempt to address a specific aspect of a supply chain, they all lack a very important ingredient, identification and 
characterisation of relevant supply chain processes. The majority of proposed frameworks, e.g. [3, 6, 8, 11], are mainly concerned with building an object model of a supply chain and not identifying the processes which realistically describe a supply chain. Though object models provide the means or building blocks to model different elements of a supply chain (e.g. activities, resources, inputs, outputs, etc.), an absence of supply chain processes promotes a "black box" view on the supply chain. Thus the information and simulation models built using this approach cannot easily be connected with other models, limiting their usefulness in an interoperable environment. It is argued here that a well defined process model provides the context to build relevant and open object models. The process component focuses the object modelling, and what is more, it greatly facilitates their subsequent validation. The ontology model introduced here was developed based on this premise. It was developed as the generic process and component library to allow rapid supply chain process modelling.

This paper introduces the overall ontology development approach. The next section introduces the process component behind the ontology model, while the third section presents the ontology development approach. Before we conclude, the fourth section will present some of the observations during the case studies conducted to validate the ontology model.

\section{Process component of the ontology model}

The ontology definition adopted in this work is based on [12] and [13]. According to [12] "an ontology is a formal specification of a shared conceptualization”, while [13] define conceptualization as "the objects, concepts and other entities that are assumed to exist in some area of interest and their inter-relationships." Building on these definitions, the high level process of developing ontology of a domain consists of identifying and designing concepts and their inter-relationships. Once developed, these become the building blocks for building and modelling supply chain processes.

The ontology model was developed as part of a wider research project that aimed to develop a generic business process model of a dyadic (buyer-supplier) relationship. This model is an attempt to explore the link between business level buyer-supplier relationship management, and operational level process management. It aims to integrate people, technology and processes at an operations level to generate different buyer-supplier configurations. The model will be built with time and cost calculation logic for different business process configurations. The scope of the model encompasses supply chain processes that support material and information flows in a buyersupplier relationship. Therefore, the ontology model must have a functionality to describe the different process configurations that companies in a dyadic relationship may want to explore. However, one may ask: what are material and information flows that make up the supply chain processes are relevant to describe a dyadic relationship? In order to find the answer, an extensive literature review was conducted [14].

Although eight supply chain process frameworks had been originally identified, only two, the Supply Chain Operations Reference (SCOR) model [15] and the Global Supply Chain Forum (GSCF) framework [16], were selected for the subsequent analysis. The SCOR model is organized around five primary management processes: (1) plan; (2) source; (3) make; (4) deliver; and (5) return. Besides the five primary management processes, the SCOR model further distinguishes three process types: planning, execution, and enable. The GSCF framework is developed to describe the standard set of supply chain processes which could be used by both researchers and practitioners. It consists of eight key processes: (1) Customer Relationship Management; (2) Customer Service Management; (3) Demand Management; (4) Order Fulfilment; (5) Manufacturing Flow Management; (6) Supplier Relationship Management; (7) Product Development and Commercialization; and (8) Returns Management. In order to extract the relevant set of supply chain processes from these two frameworks, an evaluation framework consisting of nine criteria was developed.

A set of five supply chain processes from the GSCF framework was selected as relevant for dyadic relationship. The selected processes are: (1) Customer Service Management (CSM); (2) Demand Management (DM); (3) Order Fulfillment (OF); (4) Manufacturing Flow Management (MFM); and (5) Returns Management (RM). These can be briefly introduced as follows. The purpose of the CSM process is to identify and implement necessary infrastructure required to deliver agreed Product and Service Agreements (PSAs) to a customer account [17]. PSAs are documents that match specific customer or customer segment needs with a company's products and services and they represent a company's commitment to a customer. The DM process is concerned with balancing the customer's requirements with supply chain capabilities [18] while the OF process includes generating, filling, delivering and servicing customer orders [19]. The MFM process is associated with coordinating all the manufacturing activities necessary to move products through plants as well as managing the manufacturing flexibility [20]. Finally, the RM process deals with returns, reverse logistics and avoidance [21].

These processes may be considered to be the lens through which one observes and gain understanding of the complex material and information flows, it also serves as the modelling "front end". However, processes alone do not have the details to enable the modelling necessary for data manipulation to support 
the evaluation of different "what-if" scenarios. Therefore, a combined process and ontology modelling approach was used to capture the relevant concepts and their inter-relationships required to represent various real-world situations.

\section{Ontology model development}

Throughout the years many ontology development methodologies have been proposed that differ in various ways, e.g.: level of formality proposed, an approach chosen, domain for which the ontology is being developed, the portion of the ontology life-cycle addressed by the methodology, the maturity of methodology, inheritance of a methodology, etc. It would not be wrong to conclude and thus join others who have claimed that ontology development remains an art rather than engineering discipline [22], which more than often is done in an anarchistic manner [23] and which is not mature enough to ensure a valid ontology construction process. Others also claim [24] that there is no "one and correct" methodology for developing ontologies and the best one can do is to follow a set of guidelines [25]. Due to all these reasons, the ontology model methodology adopted here loosely followed the seven step approach proposed by [24] which is depicted in the figure below.

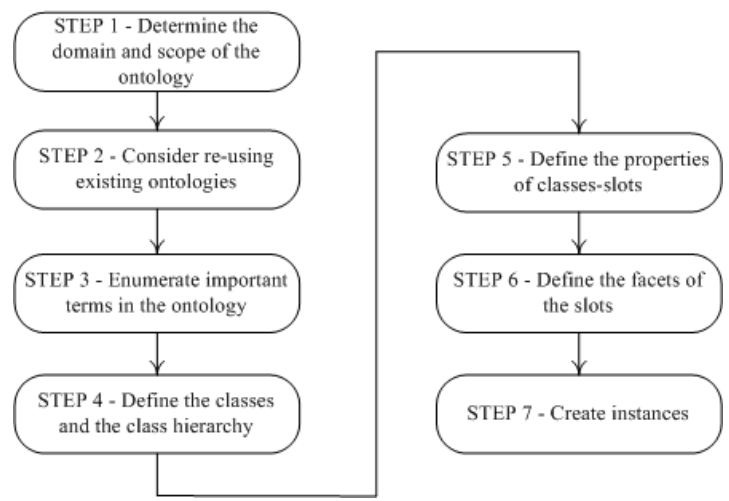

Figure 1. Ontology development approach by [24]

The overall ontology development approach is introduced next.

\subsection{Determine the domain and scope of the ontology}

According to [24] following questions have to be answered at the onset of ontology development:

- What is the domain that the ontology will cover?

- For what are we going to use the ontology?

- Who will use and maintain the ontology?

- For what types of questions will the information in the ontology provide answers?
The scope of the model has been narrowed when the set of five supply chain processes from the GSCF framework has been identified. Its purpose is to provide the building blocks, in the form of concepts and their relationships, which will be used to model real-world dyadic customer-supplier scenarios. Potential users of the ontology are the members of organisations involved in day to day supply chain operational activities, including operations managers, supply chain managers, business planners, etc. Beyond this, the users may also include any parties (e.g. researchers, teachers, etc.) interested in supply chain processes. The maintenance of ontology is a "touchy" issue, but usually should involve domain experts. The questions the ontology should provide answers to include:

- What activities is Demand Management process of company "A" consisted of?

- What resources are consumed in specific activities of Returns Management process of company "B"?

- What product or service does company " $\mathrm{A}$ " offer?

- What is the difference between Order Fulfilment process for product $\mathrm{xy}$ and $\mathrm{xyz}$ as executed by company " $\mathrm{B}$ " relative to its customer, i.e. company "A"?

- How long does it take to process a return request for specific customer?

- How much does it cost to execute an activity of Manufacturing Flow Management process?

These questions do not provide a complete list of questions the ontology model should provide an account for, but merely a guideline to get an idea of the concepts and their relationships which should be in place in order to support the representation of realworld scenarios pertinent to the five supply chain processes. It is obvious from these questions that without previously defined processes it would be fairly difficult to delineate the domain and scope of the ontology model.

\subsection{Consider re-using existing Ontologies}

In order to present a state-of-the-art research in supply chain ontology, [26] have conducted a systematic literature review. They identified six supply chain ontology models, namely: (1) Enterprise Ontology [27], (2) TOVE Ontologies [28], (3) Model by [29], (4) IDEON ontology [30], (5) Manufacturing system engineering ontology [31,32], and (6) Model by [33]. In order to synthesise gaps in the aforementioned ontologies, they designed a comparison framework consisting of seven evaluation criteria. The comparison identified nine gaps, two of which are particularly important here.

The first concerns the level of granularity addressed by established supply chain ontology models. They found that no work has been invested into the tactical 
and operational levels, which are the levels to support planning and transaction of supply chain operations. The second argues about a restricted view on a supply chain. According to [26], apart from manufacturing activities no formal account, of other material and information flow supported activities (e.g. replenishment, transport, reverse logistics, etc), is evident. These gaps not only provide an insight into the lack of ontology which may be considered for re-using, but more importantly, they offer an insight into the uniqueness of ontology model developed here. This model aims to address these gaps by explicitly focusing on the tactical and operational level supply chain processes that support material and information flows.

\subsection{Enumerate important terms in the ontology}

When developing ontology it is helpful to make a list of terms which are pertinent to the domain. The work of [24] argue how one should not be worried if there are some overlaps of concepts or whether the term in the list included is concept, or even a relationship between multiple concepts. The overall aim is to get a comprehensive list of terms relevant to the domain. The enumeration of terms was conducted by using the SCOR model and the GSCF framework with special emphasis put on the latter. Although the decision has been made to use the five supply chain processes of the GSCF framework, it is believed that many of the terms found in these two frameworks are universal for the domain they cover. Besides, the two frameworks probably provide the best references on supply chain processes currently available.

The total number of terms identified in the SCOR model was 361 and in the GSCF framework 1453. At the end the list of terms resulting from the analysis of both frameworks counted 1814 items which when the duplicates and terms with similar meaning were removed reduced to 1230 items potentially relevant terms.

\subsection{Define the classes and the class hierarchy}

The list of terms which resulted from the previous step was too long, they had to be categorised in order to make the whole process more manageable. As a preliminary step in defining the relevant classes and class hierarchy, the list of terms was reduced to 26 classes. This laid a foundation for the second round of the analysis. When analysed again some of the preliminary classes were outside the scope, so they were removed from the list. Following this, each of the remaining classes was then scrutinised with the aim of finding the relationships with other classes. As a result of this, some new concepts arose. Definition of classes and class hierarchy started after all preliminary classes and their inter-relationships had been developed.
The result was a total list of 62 classes modelled in the Protégé software [34] and presented in Figure 2. At the highest level they are arranged into two abstract classes: Supply_Chain_View and General_View. The former acts as the superclass to the classes: System, Flow, Person, Buyer and Supplier; while the latter acts as the superclass to the classes: Metric, Asset, Location, Annotation, Resource, Coordination, Process/Activity and QuantityRelationships. Although used as superclasses, classes such as: Supply_Chain_View or General_View; serve merely as an umbrella class to encompass subclasses with a similar characteristics.

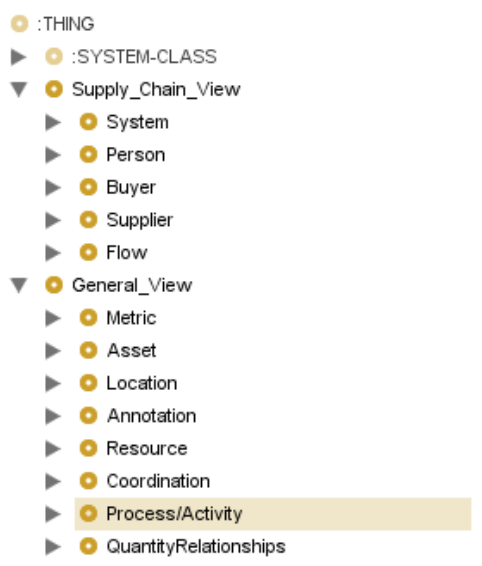

\section{Figure 2. Classes and class hierarchy of the ontology model}

\subsection{Define the properties of classes-slots}

Class properties, known as slots in Protégé, were created for majority of the classes. They are used to embody the semantic information relevant to the class. What is needed in this step is to model the internal structure or defining slots of a class. According to [35] a class can have two types of properties: (1) intrinsic and (2) mutual or relational. The first depends on a class only while the second may depend on two or more other classes. The former type of properties may be used to indicate a name, while the latter type is often used to represent a relationship with another class. There is no recipe which could clarify how to define the properties of a class. In addition to the types of properties introduced by [35] above and the results of the analysis described in the previous step, domain knowledge and experience were also used while defining slots.

\subsection{Define the facets of the slots}

Once the slots had been defined, their facets were defined. The facet of a slot sets different features a value of the slot can take. This corresponds to the value type (e.g. Integer, Float, String, Instance, etc.) and the 
allowed number of items which could be associated with the value of a slot [24].

\subsection{Create instances}

Once developed, the ontology model enables modelling domain specific knowledge and information about the material and information flow supported supply chain processes. In order to build confidence in the ontology model, the ontology model was validated in two steps. In the first step, the model was validated among the project team members with the help of an example that represents a real supply chain situation. The second step, the results of which are introduced in the following section, involved in-depth case studies of material and information flows in real industrial settings.

\section{Case studies results}

Built in this way, the ontology model has become a library of building blocks that should enable modelling of supply chain processes. At this point, the developed model is merely a theoretical proposition which has to be subjected to the empirical test before it can be used for supply chain process modelling. Therefore, case study based approach was adopted since it seems as the most appropriate. Case studies enable observation of actual practices [36], greater understanding of the nature and complexity of research phenomenon [3638] and provide much needed exploratory depth [36].

The case study objective was to validate and further enrich both the process as well as the ontology component. While the case study results concerning the former were reported elsewhere [39], the case study results relevant to ontology component are reported here. We adopted multiple case study replication logic [38] since it helps to identify similar or contrasting results and for extracting predictable, explainable reasons among replications; and as such addresses the issue of external validity. Three case studies in the automotive sector were selected. The first case study was in automotive manufacturing, where second and third case was in automotive aftermarket service. Each case study consists of two companies: a buyer and supplier. The scope of case studies is determined by the material and information flow supporting the order fulfilment process at the buyer's side and replenishment process at the supplier's side. Each company was approached separately with a three stage semi structured interview that corresponds to three levels of detail, i.e. company level, specific process level and activity level.

The ontology model served as a knowledge representation and acquisition tool. This was particularly relevant in this stage of the research since it enables a direct validation of the model when the relevant case study data was inputted in the Protégé model. The figure below shows a fraction of data presented in the ontology model from one of the case studies.

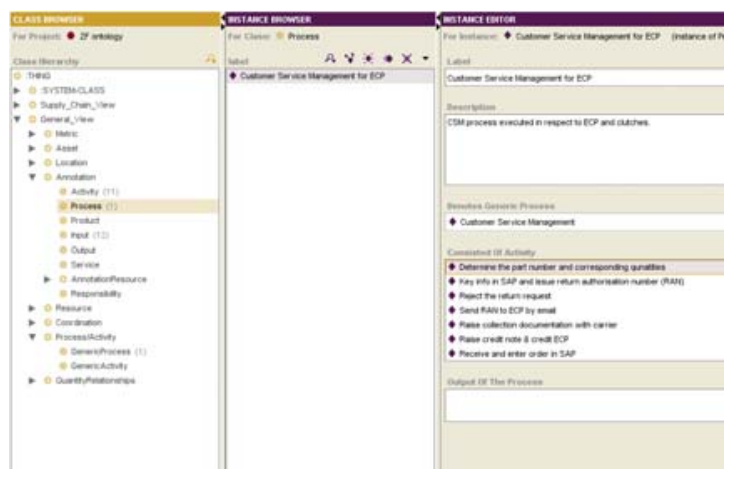

Figure 3. Case study ontology model

It is important to emphasise here that although a great deal of data has been collected through case studies, only those data that are relevant for modelling the specific supply chain processes was used. After the maps of the relevant supply chain processes had been developed and validated, the ontology model was populated.

By exposing the ontology model to empirical test, the following observations were made.

\subsection{Multidimensionality of supply chain processes}

Upon collecting the necessary data and producing the relevant process maps, the multidimensional nature of supply chain processes was revealed to us. The ontology model is built on a premise of the existence of some generic set of supply chain processes. This is reflected with GenericProcess and GenericActivity classes, which aim to accommodate the five supply chain processes. These classes are used to model a supply chain process, e.g. CSM, in generic terms which is irrespective of any particular customer. Specific CSM process, as executed for specific customer, is modelled relative to its generic counterpart. This means that the company may execute many CSM processes which may differ to meet the needs of specific customers. Further to this, we also found that even if executed for a specific customer, the supply chain processes may differ further. E.g. inside a specific CSM process which is executed for specific customer and/or product, there may exist a variety of flows which differ in respect to e.g. type of request, type of order, etc. In order to realistically support supply chain process modelling, appropriate changes to our model have to be made. 


\subsection{Not all supply chain processes are relevant}

From the analysis of case study data in the process component [39], we found that not a single company executes all five supply chain processes. A reason for this maybe the limited number of case studies conducted or the specific scope that focuses only on a subset of the total material flow between a company and its supplier or customer. Although these reasons are possible it is argued here that the more plausible explanation is that not all supply chain processes are relevant for all companies to structure the material and information flows with its suppliers and customers. This has implications on the content of an ontology model.

\subsection{Process boundaries are blurry}

Another observation coming out of the analysis of the process component concerns the process boundaries. Due to the highly interdependent nature of the supply chain processes, we were often faced with a situation where a clear boundary between the processes was hard to set. Further, if we ought to perceive the five processes as a system consisted of five interdependent subsystems then a further research into adequate system/subsystem decomposition is required. Ontology can be of great help here. Works introduced in $[40,41]$ employ ontology theory to find an optimal decomposition of information systems. Similar analysis, aiming to find an optimal decomposition of five supply chain processes, could be done here also.

\subsection{Process perspective facilitates ontology development and validation}

It can be argued that ontology model provides useful support for supply chain process modelling. Although some changes had to be made to the process model, no major structural or conceptual work was necessary to accommodate those changes. This also provides a 'proof of concept' for the approach presented here. Namely, we hold that having identified a process component will greatly facilitate development of ontology and its subsequent validation.

\section{Conclusion}

This paper introduced an ontology model which is developed as part of a wider research project that aimed to develop a supply chain process model of a dyadic (buyer-supplier) relationship. Compared with existing supply chain and ontology modelling literature, it is built based on a premise that prior identification of processes the ontology is supposed to support facilitates not only its development but subsequent validation also. Therefore, preceding the ontology development approach, five supply chain processes which support the material and information flows in a dyadic relationship had been identified. These were then used as a foundation for ontology development. Once developed, the ontology was then validated with in-depth case studies in three dyadic relationships. The results were then used to develop specific supply chain process models in three case studies. The empirical work leads to some observations that have arisen from the exposure of ontology model to real industrial settings.

Some of the findings have helped us to improve the ontology model, while others may provide an insight into potential future research avenues. We conclude that, based on our findings and experiences, prior identification of processes the ontology model is to support genuinely eases its development and validation, and what is more, it even enhances the capability and supportability of ontology.

\section{Acknowledgements}

The authors are grateful to the UK's Engineering and Physical Sciences Research Council and the industrial sponsors for providing support to the research through the grant GR/R68139/01 funding the Cranfield University Innovative Manufacturing Research Centre. The contribution from industrial collaborators and fellow team members Professor Alan Harrison, $\mathrm{Mr}$ Simon Templar and Mr Marko Bastl is acknowledged.

\section{References}

[1] Beamon, B. M., "Supply chain design and analysis: models and methods", International Journal of Production Economics, Vol. 55, No. 3, (1998), pp. 281-294.

[2] Min, H. and Zhou, G., "Supply chain modelling: past, present and future”, Computers \& Industrial Engineering, Vol. 43, No. 1-2, (2002), pp. 231-249.

[3] Biswas, S. and Narahari, Y., "Object oriented modelling and decision support for supply chains”, European Journal of Operational Research, Vol. 153, No. 3, (2004), pp. 704-726.

[4] Huang, G. Q., Lau, J. S. K. and Mak, K. L., "The impacts of sharing production information on supply chain dynamics: a review of the literature", International Journal of Production Research, Vol. 41, No. 7, (2003), pp. 1483-1517. [5] Kleijnen, J. P. C., "Supply chain simulation tools and techniques: a survey”, International Journal of Simulation and Process Modelling, Vol. 1, No. 1/2, (2005), pp. 82-89.

[6] van der Zee, D. J. and van der Vorst, J. G. A. J., "A modelling framework for supply chain simulation: opportunities for improved decision making”, Decision Sciences, Vol. 36, No. 1, (2005), pp. 65-95.

[7] Huang, S. H., Sheoran, S. K. and Keskar, H., “Computerassisted supply chain configuration based on supply chain operations reference (SCOR) model”, Computers \& Industrial Engineering, Vol. 48, No. 2, (2005), pp. 377-394.

[8] Kim, J. and Rogers, K. J., "An object-oriented approach for building a flexible supply chain model”, International Journal of Physical Distribution \& Logistics Management, Vol. 35, No. 7, (2005), pp. 481-502. 
[9] Jain, S., “A conceptual framework for supply chain modelling and simulation", International Journal of Simulation and Process Modelling, Vol. 2, No. 3/4, (2006), pp. 164-174.

[10] Pundoor, G. and Herrmann, J. W., "A hierarchical approach to supply chain simulation modelling using the Supply Chain Operations Reference model”, International Journal of Simulation and Process Modelling, Vol. 2, No. 3/4, (2006), pp. 124-132.

[11] Umeda, S. and Zhang, F., "Supply chain simulation: generic models and application examples", Production Planning \& Control, Vol. 17, No. 2, (2006), pp. 155-166.

[12] Gruber, T. R., "A Translation Approach to Portable Ontology Specification”, Knowledge Acquisition, Vol. 5, No. 2, (1993), pp. 199-220.

[13] Genesereth, M. R. and Nilsson, N. J., Logical Foundation of Artificial Intelligence, Morgan Kauffman, Los Altos, California, (1987).

[14] Grubic, T., Bastl, M., Fan, I.-S., Harrison, A. and Templar, S., "Towards the integrative supply chain model”, International Journal of Logistics: Research and Applications, (2009), Accepted for publication.

[15] www.supply-chain.org

[16] Croxton, K. L., García-Dastague, S. J., Lambert, D. M. and Rogers, D. S., "The supply chain management processes", The International Journal of Logistics Management, Vol. 12, No. 2, (2001), pp. 13-36.

[17] Bolumole, Y. A., Knemeyer, A. M. and Lambert, D. M., "The customer service management process", The International Journal of Logistics Management, Vol. 14, No. 2, (2003), pp. 15-31.

[18] Croxton, K. L., Lambert, D. M., García-Dastague, S. J. and Rogers, D. S., "The demand management process", The International Journal of Logistics Management, Vol. 13, No. 2, (2002), pp. 51-66.

[19] Croxton, K. L., "The order fulfilment process", The International Journal of Logistics Management, Vol. 14, No. 1, (2003), pp. 19-32.

[20] Goldsby, T. J. and García-Dastague, S. J., "The manufacturing flow management process", The International Journal of Logistics Management, Vol. 14, No. 2, (2003), pp. 33-52.

[21] Rogers, D. S., Lambert, D. M., Croxton, K. L. and García-Dastague, S. J., "The returns management process", The International Journal of Logistics Management, Vol. 13, No. 2, (2002), pp. 1-18.

[22] Guarino, N. and Welty, C., "Evaluating ontological decisions with ontoclean”, Communications of the ACM, Vol. 45, No. 2, (2002), pp. 61-65.

[23] Gómez-Pérez, A., "Evaluation of ontologies", International Journal of Intelligent Systems, Vol. 16, No. 3, (2001), pp. 391-409.

[24] Noy, N.F. and McGuinness, D.L., "Ontology Development 101: A Guide to Creating Your First Ontology”, Stanford University, Stanford, CA, Stanford Medical Informatics Report SMI-2001-0880, (2002).

[25] Kishore, R., Sharman, R. and Ramesh, R., "Computational Ontologies and Information Systems: I. Foundations", Communications of the Association for Information Systems, Vol. 14, (2004), pp. 158-183.

[26] Grubic, T. and Fan, I.-S., "Supply chain ontology: review, analysis and synthesis", Computers in Industry, (2009), Accepted for publication.
[27] Uschold, M., King, M., Moralee, S. and Zorgios, Y., "The enterprise ontology", The Knowledge Engineering Review, Vol. 13, No. 1, (1998), pp. 31-89.

[28] Fox, M. S., Barbuceanu, M., and Grüninger, M., “An organization ontology for enterprise modelling: preliminary concepts for linking structure and behaviour", Computers in Industry, Vol. 29, No. 1-2, (1996), pp. 123-134.

[29] Soares, A. L., Azevedo, A. L. and De Sousa, J. P., "Distributed planning and control systems for the virtual enterprise: organizational requirements and development lifecycle", Journal of Intelligent Manufacturing, Vol. 11, No. 3, (2000), pp. 253-270.

[30] Madni, A. M., Lin, W. and Madni, C. C., "IDEONTM: an extensible ontology for designing, integrating and managing collaborative distributed enterprises", Systems Engineering, Vol. 4, No. 1, (2001), pp. 35-48.

[31] Lin, H. K., Harding, J. A. and Shahbaz, M., "Manufacturing system engineering ontology for semantic interoperability across extended project teams", International Journal of Production Research, Vol. 42, No. 24, (2004), pp. 5099-5118.

[32] Lin, H. K. and Harding, J. A., "A manufacturing system engineering ontology model on the semantic web for interenterprise collaboration", Computers in Industry, Vol. 58, No. 5, (2007), pp. 428-437.

[33] Ye, Y., Yang, D., Jiang, Z. and Tong, L., "An ontologybased architecture for implementing semantic integration of supply chain management", International Journal of Computer Integrated Manufacturing, Vol. 21, No. 1, (2008), pp. 1-18.

[34] http://protege.stanford.edu/

[35] Wand, Y., Storey, V. C. and Weber, R., “An ontological analysis of the relationship construct in conceptual modeling”, ACM Transactions on Database Systems, Vol. 24, No. 4, (1999), pp. 494-528.

[36] Meredith, J., "Building operations management theory through case and field research", Journal of Operations Management, Vol. 16, No. 4, (1998), pp. 441-454.

[37] Ellram, L., "The use of the case study method in the logistics research", Journal of Business Logistics, Vol. 17, No. 2, (1996), pp. 93-138.

[38] Yin, R.K., Case Study Research - Design and Methods, Third Edition, Sage Publications, Thousand Oaks: California, USA, (2003).

[39] Grubic, T., Bastl, M., Fan, I.-S., Templar, S. and Harrison, A., "An empirical study of supply chain processes in the automotive industry", 15th International Annual Euroma conference, 15-18 June, 2008, Groningen, The Netherlands.

[40] Wand, Y., and Weber, R., "An ontological model of an information system", IEEE Transactions on Software Engineering, Vol. 16, No. 11, (1990), pp. 1282-1292.

[41] Wand, Y., and Weber, R., "On the deep structure of information systems”, Info Systems Journal, Vol. 5, (1995), pp. 203-223. 